\title{
Concentrations and potential risk assessment of polycyclic aromatic hydrocarbons (PAHs) from indoor dust of Bushehr, Iran
}

\author{
Hossein Arfaeinia ${ }^{1}$, Majid Kermani ${ }^{1}$ and Seyed Enayat Hashemi ${ }^{2, *}$ \\ ${ }^{1}$ Department of Environmental Health Engineering, School of Public Health, Iran University of Medical Sciences, Tehran, Iran \\ 2,*'Department of Environmental Health Engineering, School of Public Health, Bushehr University of Medical Sciences, Bushehr, Iran. \\ Received: 11/06/2017, Accepted: 02/10/2017, Available online: 24/10/2017 \\ *to whom all correspondence should be addressed: e-mail: E.hashemi@bpums.ac.ir
}

\begin{abstract}
Indoor dust samples were collected in the summer of 2017 from 10 residential buildings, 7 commercial buildings and 7 official buildings of Bushehr. Sixteen polycyclic aromatic hydrocarbons (PAHs) were analyzed by GC-MS. The sum concentration of the $16 \mathrm{PAHs}$ in dust spanned between 87.8 to $14619 \mathrm{mgkg}^{-1} \mathrm{~d} . \mathrm{w}$. with a mean of $2211.6 \mathrm{mgkg}^{-}$ ${ }^{1} \mathrm{~d}$.w. The mean concentration of PAHs for the dust samples from the commercial buildings was higher than from residential buildings and, from residential building was higher than from official buildings. The cancer risk through dermal and ingestion route ranged from $10^{-6}$ to $10^{-5}$ across all the dust samples, while the average of cancer risk through inhalation pathway was $10^{-9}$ to $10^{-12}$, about $10^{4}$ to $10^{6}$ times lower, when compared with other two pathways (ingestion and dermal contact). Also, the level of cancer risk for children was significantly higher than the corresponding risk for adults. The results of this work would be suitable to enhance the quality of living environment and human health in Bushehr province.
\end{abstract}

Keywords: Polycyclic aromatic hydrocarbons, Indoor dust, Risk assessment, Bushehr

\section{Introduction}

Since people (especially kids, housewives and old people) spend approximately $85 \%$ of their lifetime indoors (Amorello et al., 2015; Rudel et al., 2003), indoor air quality has a prominent role in their health (Maertens et al., 2008). Moreover, healthy housing environment is one of the key indexes to evaluate social stability and development (Li et al., 2009; Tao et al., 2016); however, rapid industrialization and urbanization ha caused deterioration of human settlement environments in cities through increasing pollutant emissions (Kang et al., 2011; Whitehead et al., 2011; Xu and Shu, 2012). In particular, contaminants accumulate in the indoor environment via multiple routes, after which they can enter human body through inhalation, ingestion, or direct skin absorption, where they are hazardous to human health and inevitably pose health risks (Song and $\mathrm{Xu}, 2011$; Whitehead et al., 2011). Therefore, indoor environments should be controlled for efficient risk management and human health protection (Mannino and Orecchio, 2008).

Indoor dust is one of the major matrixes that can be utilized as a useful indicator for indoor air contaminants transport and deposition(Xu and Shu, 2014). Indoor dust also acts as a reservoir for pollutants and can provide useful information for estimating human exposure to contaminants(Butte and Heinzow, 2002). The presence of various environmental contaminants such as heavy metals, flame retardants, plasticizers, asbestos, smoke residues, pesticides, phthalates, and PCBs has been surveyed in indoor dust (Lioy et al., 2002; Mirzaei et al., 2015; Rasmussen et al., 2001; Rudel et al., 2003). Among these contaminants, polycyclic aromatic hydrocarbons (PAHs) are one of the major human health concerns, owing to their ubiquitous occurrence and high carcinogenic and mutagenic potential (Kameda et al., 2005). In indoor environments, elevated levels of PAHs have been found to be mainly produced by endogenous sources such as domestic heating, cooking, wood-burning, tobacco smoke, decorative candle and incense burning (Castro et al., 2011). These semi volatile compounds accumulate on dusts, and the dust that is settled indoors can be a sink for these pollutants (Roberts et al., 2009). Although the concentration and sources of outdoor PAHs have been widely studied, dust-bounded PAHs in indoor environments (such as residential, commercial and official buildings) are still a challenging issue. Moreover, indoor air quality in these environments significantly influences the human welfare and work performance (Fanger, 1998; Wolkoff, 2013). For example, it has been shown that some of the most common symptoms in offices caused by polluted indoor air are headache, irritation, tiredness, and dry or itchy eyes (Wolkoff, 2013), with these symptoms causing $2 \%$ reduction in efficiency and subsequently economic loss (Buchanan et al., 2008).

This paper was aims to investigate the concentration of PAHs in indoor dust at buildings, located in Bushehr city center, Iran. Moreover, the potential health risks of PAHs in indoor dust were also evaluated.

\section{Materials and methods}

\subsection{Sample collection}


Indoor dust samples used in this study were collected in June 2016 from 24 indoor environments (including 18 residential buildings (URB1 to URB10), seven commercial buildings (UCB11 to UCB17) and seven official buildings (UOB18 to UOB24) of Bushehr city (Table1), according to the standardized protocol (Stuart et al., 2008) (Table1). To control the impact of rainfall, sampling was conducted in dry seasons (summer [July]) and all samples were collected after two consecutive weeks without precipitation. About $20 \mathrm{~g}$ of dust samples was taken in each site using a polyethylene brush and a stainless steel scoop (for transferring the dust samples into plastic bags) rinsed with acetone under exact procedures. To avoid cross- contamination, all sampling equipment was cleaned after each sampling by ultrasound, rinsed with deionized water and then air dried. During the sampling, the characteristics of the building such as building type, floor types, number of smokers, number of electronic devices, cooking conditions, ventilation type and distance off road were also recorded. Each sample was transferred into clean plastic bags, sealed and then refrigerated $\left(4^{\circ} \mathrm{C}\right)$ on site. The samples were protected from sunlight with aluminum foils and then rapidly transported to the laboratory. In the laboratory, the dust samples were put at $-20{ }^{\circ} \mathrm{C}$ until further analysis (Raeisi et al., 2016).

Table 1. Areas, descriptive profile and ongoing activities of indoor sampling sites

\begin{tabular}{|c|c|c|c|}
\hline Station & Area type & Environment & Characteristics \\
\hline URB1 & Urban & Bedroom & $\begin{array}{l}\text { Away from street, no smokers, natural ventilation } 1 \text { windows, } \\
\text { cooking with gas }\end{array}$ \\
\hline URB2 & Urban & Kitchen & $\begin{array}{l}\text { Near the street, no smokers, natural ventilation } 2 \text { windows } \\
\text { cooking with gas }\end{array}$ \\
\hline URB3 & Urban & Bedroom & $\begin{array}{l}\text { Away from street, smokers, natural ventilation no windows } \\
\text { cooking with electricity }\end{array}$ \\
\hline URB4 & Urban & Living room & $\begin{array}{l}\text { Heavy traffic, smokers, natural ventilation } 2 \text { windows, cooking } \\
\text { with gas }\end{array}$ \\
\hline URB5 & Urban & Kitchen & $\begin{array}{l}\text { Near the street, smokers, natural ventilation no windows, cooking } \\
\text { with biomass }\end{array}$ \\
\hline URB6 & Urban & Bedroom & $\begin{array}{l}\text { Heavy traffic, smokers, natural ventilation } 1 \text { windows, cooking } \\
\text { with biomass }\end{array}$ \\
\hline URB7 & Urban & Bedroom & $\begin{array}{l}\text { Moderate traffic, no smokers, natural ventilation } 2 \text { windows, } \\
\text { cooking with electricity }\end{array}$ \\
\hline URB8 & Urban & Bedroom & $\begin{array}{l}\text { Away from street, no smokers, natural ventilation } 2 \text { windows } \\
\text { cooking with electricity }\end{array}$ \\
\hline URB9 & Urban & Living room & $\begin{array}{l}\text { Light traffic, smokers, natural ventilation no windows, cooking } \\
\text { with gas }\end{array}$ \\
\hline URB10 & Urban & Living room & $\begin{array}{l}\text { Near the street, no smokers, natural ventilation } 2 \text { windows } \\
\text { cooking with electricity }\end{array}$ \\
\hline UCB11 & Urban & Clothes shop & Heavy traffic, smokers, natural ventilation 1 windows, no cooking \\
\hline UCB12 & Urban & Market & $\begin{array}{l}\text { Light traffic, no smoker, natural ventilation } 1 \text { windows, no } \\
\text { cooking }\end{array}$ \\
\hline UCB13 & Urban & Restaurant & $\begin{array}{l}\text { Moderate traffic, no smokers, natural ventilation } 1 \text { windows, } \\
\text { cooking with gas }\end{array}$ \\
\hline UCB14 & Urban & Clothes shop & $\begin{array}{l}\text { Heavy traffic, no smokers, natural ventilation no windows, no } \\
\text { cooking }\end{array}$ \\
\hline UCB15 & Urban & Barbecued & $\begin{array}{l}\text { Heavy traffic, smokers, natural ventilation no windows, cooking } \\
\text { with coal }\end{array}$ \\
\hline UCB16 & Urban & Pizza store & $\begin{array}{l}\text { Moderate traffic, no smokers, natural ventilation no windows, } \\
\text { cooking with gas }\end{array}$ \\
\hline UCB17 & Urban & Market & $\begin{array}{l}\text { Moderate traffic, no smoker, natural ventilation } 1 \text { windows, no } \\
\text { cooking }\end{array}$ \\
\hline UOB18 & Urban & Laboratory & Away from street, no smokers, air conditioning, no cooking \\
\hline UOB19 & Urban & Office & $\begin{array}{l}\text { Near the street, no smokers, natural ventilation } 2 \text { windows, no } \\
\text { cooking }\end{array}$ \\
\hline UOB20 & Urban & Laboratory & Moderate traffic, no smokers, air conditioning, no cooking \\
\hline UOB21 & Urban & Office & Light traffic, smokers, natural ventilation no windows, no cooking \\
\hline UOB22 & Urban & Office & Heavy traffic, no smokers, air conditioning, no cooking \\
\hline UOB23 & Urban & School & $\begin{array}{l}\text { Heavy traffic, smokers, natural ventilation no windows, no } \\
\text { cooking }\end{array}$ \\
\hline UOB24 & Urban & Office & light traffic, no smokers, air conditioning, no cooking \\
\hline
\end{tabular}

\subsection{Chemicals}

Standards of 16 PAHs (concentration: $100-2000 \mu \mathrm{g} / \mathrm{ml}$ ) were purchased from Sigma-Aldrich (USA) including naphthalene (NA), acenaphthene (ACE), acenaphthylene $(A C Y)$, phenanthrene $(P H)$, fluorine $(F L)$, anthracene (AN), pyrene (PY), fluoranthene (FLU), benzo[a]anthracene $(\mathrm{BaA})$, chrysene $(\mathrm{CH})$, benzo[b]fluoranthene $(\mathrm{BbF})$, 
benzo[a]pyrene (BaP), benzo[k]fluoranthene (BkF), indeno[1,2,3-cd] pyrene (IP), and benzobenzo[g,h,i]perylene (BP), dibenzo[a,h]anthracene (DA). Dichloromethane, n-hexane, cyclohexane, acetone and other solvents were of spectral purity level (United States World Company).

\subsection{Sample preparation, extraction and analysis procedure}

Prior to the extraction, dusts were eliminated from the plastic bags using suitable forceps and placed into a mechanical sieve shaker equipped with a 100-mesh sieve and were shaken for $7 \mathrm{~min}$. After that, large debris such as shavings, chips, soil hunk, hair and etc. were eliminated by tweezers or a paint brush. The dust samples were then resieved for an additional $5 \mathrm{~min}$ with a 100 -mesh sieve to obtain dust particles $<150 \mu \mathrm{m}$. The sieved dusts were extracted through ultrasonic extraction procedure. The extract was passed through a $0.45 \mu \mathrm{m}$ Whatman Teflon, concentrated to $250 \mathrm{~mL}$ using gentle stream of nitrogen ( $\mathrm{N}$ E VAP 112, USA) at $30{ }^{\circ} \mathrm{C}$, and brought up to $2 \mathrm{~mL}$ in dichloromethane. Finally, the extracts were collected in suitable vials for the following measurements. The analysis was performed on an Agilent 7890 Gas Chromatograph5975C Mass selective Detector (GC-MS) system equipped with a fused silica capillary $\mathrm{Hp}-5$ column (30* $0.25 \mathrm{~mm}$ i.d., $0.25 \mathrm{~mm}$ film thickness).

Table 2. Factors used in health risk assessment

\begin{tabular}{cccc}
\hline Factors & Unit & child & Adult \\
\hline Exposure frequency (EF) & Day year & 180 \\
\hline Exposure duration (ED) & Year & 180 & 24 \\
\hline Body weight (BW) & $\mathrm{Kg}$ & 6 & 61.5 \\
\hline Dust ingestion rate (IR ingestion) & ${\mathrm{mg} . \mathrm{day}^{-1}}^{-1}$ & 15 & 100 \\
\hline Inhalation rate (IR inhalation) & $\mathrm{m}^{3} \cdot$ day $^{-1}$ & 200 & 20 \\
\hline Dermal adherence factor (AF) & ${\mathrm{mg} \cdot \mathrm{cm}^{-2}}^{2}$ & 10 & 0.07 \\
\hline Dermal exposure area (SA) & $\mathrm{cm}^{2}$ & 0.2 & 5700 \\
\hline Particle emission factor (PEF) & $\mathrm{m}^{3} \cdot \mathrm{kg}^{-1}$ & 2800 & $1.36^{*} 10^{9}$ \\
\hline Dermal adsorption fraction (ABS) & Unitless & $1.36 * 10^{9}$ & 0.13 \\
\hline Averaging life span (AT) & Day & 0.13 & $70 * 365=25,550$ \\
\hline
\end{tabular}

\subsection{Risk Assessment of PAHs in indoor Dust}

The incremental life time cancer risk (ICLRs) was used to quantitatively assess the potential risk of PAHs exposure indoors according to the U.S. EPA standard models(EPA, 1991). Following mathematical equations were used to the ICLRs for indoor environment residents based on three main pathways including direct ingestion, inhalation and dermal contact.

$$
\text { ICLRs Inhalation }=\frac{\mathrm{CS} \times\left(\mathrm{CSF}_{\text {Inhalation }} \times\left(\frac{\mathrm{BW}}{70 \mathrm{Kg}}\right)^{\frac{1}{3}}\right) \times \mathrm{R}_{\text {Inh }} \times \mathrm{CF} \times \mathrm{ED}}{\mathrm{BW} \times \mathrm{AT}_{\mathrm{C}} \times \mathrm{PEF}}
$$

$$
\text { ICLRs Ingestion }=\frac{\mathrm{CS} \times\left(\mathrm{CSF}_{\text {Ingestion }} \times\left(\frac{\mathrm{BW}}{70 \mathrm{Kg}}\right)^{\frac{1}{3}}\right) \times I \mathrm{R}_{\text {Ing }} \times \mathrm{CF} \times \mathrm{ED}}{\mathrm{BW} \times \mathrm{AT}_{\mathrm{C}} \times 10^{6}}
$$

$$
\text { ICLRs dermal }=\frac{\mathrm{CS} \times\left(\operatorname{CSF}_{\text {Dermal }} \times\left(\frac{B W}{70 K g}\right)^{\frac{1}{3}}\right) \times S A \times A B F \times A F d \times C F \times E D}{B W \times A T_{C} \times 10^{6}}
$$

In these equations, CS stands for the Concentration of PAHs indoors $(\mu \mathrm{g} / \mathrm{g})$, which was calculated according to toxicity equivalent of BaP with the Toxic equivalency factor (TEF) listed in Table 2. CSF $_{i}$ is carcinogenic slope factor (mg.kg ${ }^{-1}$ day $\left.^{-1}\right)^{-1}$, which has been 7.3, 25, and 3.85 for ingestion, dermal and inhalation, respectively, based on the cancer-causing ability of BaP (Hu et al., 2007). IR $\mathrm{R}_{\operatorname{lnh}}$ is the particle inhalation rate $\left(\mathrm{m}^{3} \cdot \mathrm{day}^{-1}\right), \mathrm{IR} \operatorname{Ing}$ is the intake rate of dusts $\left(\mathrm{m}^{3}\right.$.day $\left.{ }^{-1}\right), \mathrm{ABS}$ is the dermal adsorption fraction (dimension less), AFd is the particle to dermal adherence factor $\left(\mathrm{mg} \cdot \mathrm{cm}^{-2} \cdot \mathrm{h}^{-1}\right), \mathrm{SA}$ is the dermal surface area exposure $\left(\mathrm{cm}^{2}\right)$, and $E F$ denotes the exposure frequency $\left(\right.$ day year ${ }^{-1}$ ) indoors. Here, we have calculated non-working days and national holidays in a year and then deducted them from the total days of the year (365 days) to calculate exposure frequency for workers in official and commercial buildings. Further, EF for residents in residential buildings was calculated according to the Risk Assessment Guidance of U.S. EPA and related studies, as shown in table 2. ED is the exposure duration (year). Here, we have multiplied the average working years of study subjects by the number of working hours in a day to calculate exposure duration for workers in official and commercial buildings and ED for residents in residential buildings was calculated according to the Risk Assessment Guidance of U.S. EPA and related studies, as shown in table 2. Finally, PEF is the emission factor for particles $\left(\mathrm{m}^{3} \cdot \mathrm{kg}^{-1}\right), \mathrm{BW}$ is the Body weight $(\mathrm{kg})$, and AT is the average life span (day).

\subsection{Data analysis}

Statistical processing of data was done using SPSS ver. 20 (IBM Corp., USA). Before data analysis, the normality of all data was checked with the Shapiro-Wilk test. Descriptive statistics (mean, standard deviation and range) were employed for presentation of PAHs concentrations in indoor dusts.

\section{Results and Discussion}

\subsection{Level of PAHs in indoor dust}

The presence of 16 targeted PAHs was tracked in indoor dust samples of various areas and their individual 
concentrations (on dry weight basis) have been given in Table 3. The sum concentration of the $16 \mathrm{PAHs}$ in dust of Bushehr spanned between 87.8 to14619 $\mathrm{mgkg}^{-1} \mathrm{~d}$.w. with a mean of $2211.6 \mathrm{mgkg}^{-1} \mathrm{~d}$.w. Naphthalene was not detected in any of the samples. With a molecular mass of 128.17 and a vapor pressure of $8.5 \times 10^{-2} \mathrm{~mm} \mathrm{Hg}$ (Ambrose et al., 1975). Acenaphthylene was generally detected only at low levels in dust samples and this can be related to its more affinity for volatilization. In contrast, as a result of less volatility, benzo[b]fluoranthene has been at in the highest levels in most of dust samples. In general, PAHs with a higher number of rings have lower volatilities (Maertens et al., 2008).

Table 3. PAHs residues (mean of three analysis) in $\mathrm{mgkg}^{-1} \mathrm{~d} . \mathrm{w}$. in indoor dust of residential, commercial and official buildings of Bushehr

\begin{tabular}{|c|c|c|c|c|c|c|c|c|c|c|c|c|c|c|}
\hline & \multicolumn{10}{|c|}{ Residential buildings } & \multicolumn{4}{|c|}{ Commercial buildings } \\
\hline PAHs & URB1 & URB2 & URB3 & URB4 & URB5 & URB6 & URB7 & URB8 & URB9 & URB10 & UCB11 & UCB12 & UCB13 & UCB14 \\
\hline NA & ND & ND & ND & ND & ND & ND & ND & ND & ND & ND & ND & ND & ND & ND \\
\hline ACE & 1.2 & 13 & 0.14 & 62 & 12 & 17 & 1.1 & 0.8 & 30 & 1.3 & 21 & 2.3 & 921 & 19 \\
\hline $\mathrm{ACY}$ & 0.9 & 78 & 0.7 & 54 & 154 & 23 & 3.2 & 1 & 23 & 1.8 & 54 & 4.8 & 1786 & 23 \\
\hline $\mathrm{FL}$ & 1.4 & 121 & 1.8 & 38 & 211 & 41 & 6.7 & 0.4 & 14 & 1.2 & 84 & 4.3 & 413 & 32 \\
\hline $\mathrm{PH}$ & 3.2 & 478 & 2.8 & 178 & 615 & 256 & 1.8 & 1.1 & 67 & 1.9 & 318 & 5.7 & 1760 & 167 \\
\hline AN & 1.9 & 51 & 2.3 & 65 & 718 & 283 & 4.1 & 0.9 & 29 & 2.1 & 221 & 5.4 & 1434 & 16 \\
\hline FLU & 4.3 & 378 & 3.2 & 145 & 526 & 311 & 6.2 & 2.1 & 78 & 3.4 & 248 & 6.7 & 1423 & 172 \\
\hline PY & 1.9 & 311 & 0.9 & 171 & 498 & 234 & 2.3 & 1.8 & 87 & 2.7 & 193 & 3.2 & 1314 & 142 \\
\hline $\mathrm{BaA}$ & 2.7 & 67 & 1.2 & 37 & 21 & 21 & 2.1 & 1.2 & 12 & 2.6 & 87 & 5.4 & 412 & 12 \\
\hline $\mathrm{CH}$ & 2.9 & 76 & 1.9 & 93 & 102 & 32 & 1.9 & 2.1 & 65 & 3.2 & 156 & 4.3 & 645 & 78 \\
\hline $\mathrm{BbF}$ & 4.1 & 404 & 2.1 & 159 & 170 & 19 & 24 & 2.2 & 44 & 1.8 & 158 & 4.5 & 1534 & 113 \\
\hline $\mathrm{BaP}$ & 2.3 & 7.9 & 2.1 & 47 & 11 & 111 & 17 & 3.2 & 19 & 2.2 & 76 & 6.5 & 598 & 51 \\
\hline $\mathrm{BkF}$ & 1.8 & 11 & 1.1 & 43 & 123 & 143 & 34 & 1.1 & 17 & 3.1 & 102 & 1.3 & 222 & 78 \\
\hline IP & 1.9 & 112 & 1.2 & 188 & 211 & 267 & 37 & 2 & 89 & 4 & 67 & 5.4 & 67 & 45 \\
\hline $\mathrm{BP}$ & 3 & 137 & 2.6 & 264 & 176 & 314 & 41 & 1.8 & 91 & 1.2 & 156 & 4.5 & 234 & 119 \\
\hline DA & 2.3 & 141 & 1.5 & 192 & 152 & 271 & 33 & 1.2 & 67 & 3.2 & 113 & 6.7 & 342 & 109 \\
\hline$\Sigma \mathrm{PAHs}$ & 36.7 & 2883.9 & 25.54 & 1735 & 3700 & 2349 & 215.4 & 22.9 & 732 & 35.7 & 2054 & 71 & 13105 & 1176 \\
\hline & \multicolumn{3}{|c|}{ Commercial buildings } & \multicolumn{7}{|c|}{ Official buildings } & & & & \\
\hline PAHs & UCB15 & UCB16 & UCB17 & OCB18 & OCB19 & OCB20 & OCB21 & OCB22 & OCB23 & OCB24 & & & & \\
\hline NA & ND & ND & ND & ND & ND & ND & ND & ND & ND & ND & & & & \\
\hline ACE & 254 & 113 & 7.8 & 0.9 & 1.1 & 5.6 & 4.4 & 32 & 98 & 2.1 & & & & \\
\hline $\mathrm{ACY}$ & 298 & 172 & 9.8 & 1.1 & 0.9 & 6.7 & 2.8 & 28 & 78 & 2 & & & & \\
\hline $\mathrm{FL}$ & 387 & 198 & 9 & 0.8 & 0.3 & 7.4 & 3.2 & 19 & 89 & 1.7 & & & & \\
\hline $\mathrm{PH}$ & 1190 & 412 & 2.5 & 1.8 & 1.3 & 3.2 & 0.9 & 76 & 314 & 1 & & & & \\
\hline AN & 1421 & 319 & 1.1 & 1.9 & 1 & 1.8 & 1.1 & 33 & 287 & 0.7 & & & & \\
\hline FLU & 1023 & 451 & 6.2 & 3.2 & 1.7 & 6.2 & 5.2 & 87 & 309 & 2.1 & & & & \\
\hline PY & 978 & 333 & 2.3 & 1.2 & 1.5 & 4.3 & 4.8 & 67 & 289 & 2.2 & & & & \\
\hline $\mathrm{BaA}$ & 78 & 67 & 2.1 & 3.9 & 1.3 & 3.2 & 2.1 & 19 & 41 & 1.2 & & & & \\
\hline $\mathrm{CH}$ & 215 & 87 & 1.9 & 2.7 & 3.2 & 2.8 & 3.3 & 87 & 71 & 2.3 & & & & \\
\hline $\mathrm{BbF}$ & 1212 & 413 & 24 & 3.2 & 3.4 & 27 & 17 & 43 & 328 & 8.9 & & & & \\
\hline $\mathrm{BaP}$ & 879 & 231 & 17 & 4.9 & 2.9 & 16 & 11 & 26 & 198 & 5.6 & & & & \\
\hline $\mathrm{BkF}$ & 718 & 312 & 37 & 1.1 & 1.9 & 43 & 23 & 21 & 214 & 11 & & & & \\
\hline IP & 1652 & 545 & 34 & 4.5 & 1.3 & 47 & 38 & 87 & 425 & 18 & & & & \\
\hline $\mathrm{BP}$ & 1978 & 676 & 33 & 4.3 & 2.3 & 54 & 42 & 128 & 562 & 12 & & & & \\
\hline DA & 2345 & 509 & 41 & 3.9 & 3.2 & 44 & 37 & 87 & 487 & 17 & & & & \\
\hline$\Sigma \mathrm{PAHs}$ & 14619 & 4838 & 238.7 & 39.8 & 26.4 & 272.2 & 194.8 & 840 & 3790 & 87.7 & & & & \\
\hline
\end{tabular}

The highest levels of both $\Sigma$ PAHs (14619 $\mathrm{mgkg}^{-1}$ d.w) was found at the UCB15 station. The features of this station include heavy traffic, existence of smokers, natural ventilation, no windows, and cooking with coal. The levels of 5- and 6-ring PAHs in indoor dust collected from buildings with coal combustion was higher than others. For buildings with coal for heating, cooking and etc., the PAH was the highest in dust samples, showing that coal combustion can significantly affect the PAHs generation (Qi et al., 2014). Regarding the effect of smoking on dust, some studies show a higher concentration of PAHs in buildings
As indicated in Table 3, considerable differences were observed between the levels of PAHs in dust across residential buildings, commercial buildings and official buildings. The levels (in mgkg- 1 d.w.) of $\Sigma P A H s$ ranged from 22.9 to 2883.9 in the dust samples of the residential buildings, from 71 to 13105 for commercial buildings and 26.4 to $3790 \mathrm{mgkg}^{-1} \mathrm{~d}$.w. The mean concentration of PAHs for the dust samples of the commercial buildings was higher than for residential buildings. Also it was higher for residential buildings than for official buildings. 
during the sampling period has been shown in Fig. 1. As illustrated in this figure, high molecular weight PAHs with 4-6 ring have a higher fraction of about $70 \%$ in total PAHs, while low molecular weight PAHs with 2-3 ring participates a lower fraction. The higher fraction of high molecular weight PAHs in $\mathrm{PM}_{2.5}$ samples is mainly due to fossil fuel consumption. Similar observations have also been reported by Liu and Cheng (Liu et al., 2007) and D.P. Singh (Singh et al., 2011).

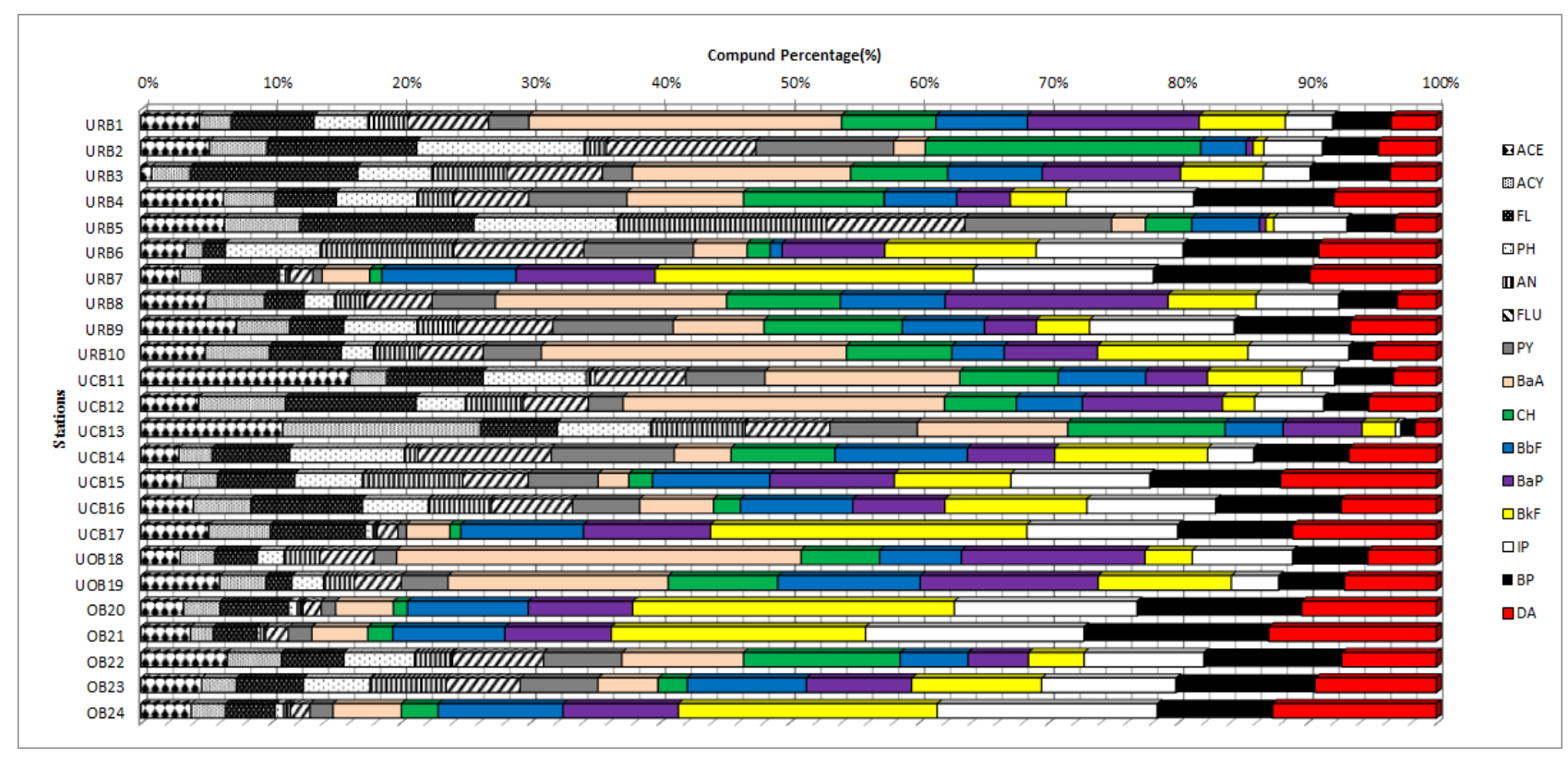

Figure 1. Percentage of PAHs compounds in dust samples from different stations

\subsection{Health risk assessment}

A probabilistic risk assessment was done based on TEF and CSF, with the findings shown in Table 4. As shown in the table, the cancer risk through dermal and ingestion route ranged from $10^{-6}$ to $10^{-5}$ across all the dust samples, while the average of cancer risk through inhalation pathway was $10^{-9}$ to $10^{-12}$, about $10^{4}$ to $10^{6}$ times lower in comparison with the other two pathways (ingestion and dermal contact). These findings were consistent with those reported by other studies (Yang et al., 2015). Thus, inhalation of PAHs-bound dust via mouth and nose was not considerable, when compared with dermal and ingestion routes. For children, the cancer risk values through dermal and ingestion pathways were about $10^{-6}$ to $10^{-5}$, demonstrating that both routes (ingestion and dermal contact) contributed considerably to the cancer risk of children. On the other hand, for adults, the cancer risk values through dermal, ingestion and inhalation pathways were about $10^{-6}$ to $10^{-5}, 10^{-6}$ to $10^{-5}$ and $10^{-10}$ to $10^{-12}$, respectively. Therefore, the risk value of cancer for infants was significantly higher $(p<0.01)$ than the corresponding risk for adults. This can be related to the more hand-to mouth activity of infants, so contaminated dust can be easily ingested by children(Xia et al., 2010). The other reason is the lower body weight of infants. So, the intake of PAHs compounds (mg per kg of body weight) in children is greater than in adults. Moreover, early development of body systems such as organs, immune and nervous systems can probably increase the sensitivity of children to carcinogens (Kamal et al., 2014).
Table 4. The potential risk of PAHs in indoor dust of each building and three exposure routes

\begin{tabular}{ccccc}
\hline & & Residential & Commercial & Official \\
\hline \multicolumn{2}{c}{ CS $\left(\mu \mathrm{g} \cdot \mathrm{kg}^{-1}\right)$} & $0.9 \times 10^{3}$ & $2.37 \times 10^{3}$ & $8.9 \times 10^{2}$ \\
Adults $\quad$ Ingestion & $7.87 \times 10^{-5}$ & $9.98 \times 10^{-5}$ & $1.14 \times 10^{-6}$ \\
& Inhalation & $2.33 \times 10^{-10}$ & $6.76 \times 10^{-10}$ & $5.43 \times 10^{-11}$ \\
& Dermal & $9.65 \times 10^{-6}$ & $4.65 \times 10^{-5}$ & $2.12 \times 10^{-6}$ \\
& contact & & & \\
& Cancer & $8.83 \times 10^{-5}$ & $1.46 \times 10^{-4}$ & $3.26 \times 10^{-6}$ \\
Child $\quad$ Ingestion & $8.76 \times 10^{-5}$ & $2.71 \times 10^{-4}$ & $8.76 \times 10^{-5}$ \\
& Inhalation & $4.43 \times 10^{-10}$ & $7.33 \times 10^{-10}$ & $4.43 \times 10^{-10}$ \\
& Dermal & $3.77 \times 10^{-6}$ & $8.45 \times 10^{-5}$ & $3.77 \times 10^{-6}$ \\
& contact & & & \\
& Cancer & $9.13 \times 10^{-5}$ & $3.61 \times 10^{-4}$ & $9.13 \times 10^{-5}$ \\
\hline
\end{tabular}

This research recommends better ventilation techniques, producing of foods in cooking oils with lesser PAHs in the kitchen and use of cooking fuels with lesser PAHs generations. Based on the study results, the study accentuates the urgent need of developing indoor air quality standards in Iran for home, office and occupational settings like kitchens in Bushehr city (Arfaeinia et al., 2015).

Moreover, since the dominant pathway for polluted dust intake are oral ingestion and dermal contact, which together contribute $99 \%$ of carcinogenic risk and $90 \%$ of non-carcinogenic risk on average, utilize of a respirator or other protective equipments and reducing exposed skin area could greatly reduce the health risk. 


\section{Conclusion}

A total of 24 indoor dust samples (10 residential indoor, 7 commercial and 7 official indoor buildings) collected from Bushehr, south of Iran, were analyzed for 16 PAHs. The total PAHs concentrations in dust ranged from 87.8 to14619 $\mathrm{mgkg}^{-1} \mathrm{~d}$.w. with a mean of $2211.6 \mathrm{mgkg}^{-1} \mathrm{~d}$.w. The concentration of PAHs in indoor dust samples in the study area indicated that commercial buildings were the most polluted area, followed by residential and official buildings. The cancer risk levels due to exposure to indoor dustbound PAHs in residential, commercial and official buildings of Bushehr province, Iran were $1.46 \times 10^{-4}, 8.83$ $\times 10^{-5}$ and $3.26 \times 10^{-6}$ for adults and $3.61 \times 10^{-4}, 9.13 \times 10^{-5}$ and $9.13 \times 10^{-5}$ for children, respectively. The findings of this research would be useful to provide the information for enhancing the quality of living environment and human health in Bushehr province.

\section{Acknowledgment}

This work is supported by a project founded by Bushehr University of Medical Sciences (Grant No:2637).

\section{References}

IARC (International Agency for research on cancer) 2011. Agents Classified by the IARC Monographs 1, 102p.

Ambrose D., Lawrenson I. and Sprake C. (1975), The vapour pressure of naphthalene, The Journal of Chemical Thermodynamics. 7, 1173-1176.

Amorello D., Barreca S., Orecchio S. and Ferro S. (2015), Platinum in indoor settled dust matter (homes and cars), Microchemical Journal, 123, 76-83.

Arfaeinia H., Moradi M., Sharafi K., Mahdi Esfahan N. and Dobaradaran S. (2015), Evaluation of Public Health Impacts Related To Urban Air Pollution In Shiraz And Bushehr, Iran, International Journal of Pharmacy \& Technology, 7, 9811-9824.

Buchanan I., Mendell M., Mirer A. and Apte M. (2008), Air filter materials, outdoor ozone and building-related symptoms in the BASE study, Indoor Air. 18, 144-155.

Butte W. and Heinzow B. (2002), Pollutants in house dust as indicators of indoor contamination, Reviews of Environmental Contamination and Toxicology, 175, 1-46.

Castro D., Slezakova K., Delerue-Matos C., da Conceição AlvimFerraz M., Morais S. and do Carmo Pereira M. (2011), Polycyclic aromatic hydrocarbons in gas and particulate phases of indoor environments influenced by tobacco smoke: levels, phase distributions, and health risks, Atmospheric Environment, 45, 1799-1808.

EPA US. (1991), Risk Assessment Guidance for Superfund: Volume I-Human Health Evaluation Manual (Part B, Development of Risk-based Preliminary Remediation Goals). 92857-01B. Washington, D. C: Office of Emergency and Remedial Response.

Fanger P.O. (1998), Discomfort Caused by Odorants and Irritants in the Air*, Indoor Air. 8, 81-86.

Hu Y., Bai Z., Zhang L., Wang X., Zhang L., Yu Q. and Zhu T. (2007), Health risk assessment for traffic policemen exposed to polycyclic aromatic hydrocarbons (PAHs) in Tianjin, China, Science of the Total Environment, 382, 240-250.
Kamal A., Malik R.N., Martellini T. and Cincinelli A. (2014), Cancer risk evaluation of brick kiln workers exposed to dust bound PAHs in Punjab province (Pakistan), Science of the Total Environment, 493, 562-570.

Kameda Y., Shirai J., Komai T., Nakanishi J. and Masunaga S. (2005), Atmospheric polycyclic aromatic hydrocarbons: size distribution, estimation of their risk and their depositions to the human respiratory tract, Science of the Total Environment. 340, 71-80.

Kang Y., Cheung K.C. and Wong M.H. (2011), Mutagenicity, genotoxicity and carcinogenic risk assessment of indoor dust from three major cities around the Pearl River Delta, Environment international, 37, 637-643.

Li F., Liu X., Hu D., Wang R., Yang W., Li D. and Zhao D. (2009), Measurement indicators and an evaluation approach for assessing urban sustainable development: A case study for China's Jining City, Landscape and Urban Planning, 90, 134-142.

Lioy P.J., Freeman N.C. and Millette J.R. (2002), Dust: a metric for use in residential and building exposure assessment and source characterization, Environmental health perspectives, 110, 969.

Liu M., Cheng S., Ou D., Hou L., Gao L., Wang L., Xie Y., Yang Y. and Xu S. (2007), Characterization, identification of road dust PAHs in central Shanghai areas, China, Atmospheric Environment, 41, 8785-8795.

Maertens R.M., Bailey J. and White P.A. (2004), The mutagenic hazards of settled house dust: a review, Mutation Research/Reviews in Mutation Research, 567, 401-425.

Maertens R.M., Yang X., Zhu J., Gagne R.W., Douglas G.R. and White P.A. (2008), Mutagenic and carcinogenic hazards of settled house dust I: Polycyclic aromatic hydrocarbon content and excess lifetime cancer risk from preschool exposure, Environ.Sci.Technol., 42, 1747-1753.

Mahler B.J., Metre P.C.V., Wilson J.T., Musgrove M., Burbank T.L., Ennis T.E. and Bashara T.J. (2010), Coal-tar-based parking lot sealcoat: An unrecognized source of PAH to settled house dust, Environ.Sci.Technol., 44, 894-900.

Mannino M.R. and Orecchio S. (2008), Polycyclic aromatic hydrocarbons (PAHs) in indoor dust matter of Palermo (Italy) area: extraction, GC-MS analysis, distribution and sources, Atmospheric Environment. 42, 1801-1817.

Mirzaei N., Arfaeinia H., Moradi M., Moghadam F.M., Velayati A. and Sharafi K. (2015), The statistical analysis of seasonal and time variations on trend of important air pollutants ( $\mathrm{SO} 2, \mathrm{O} 3$, NOx, CO, PM10)-in western Iran: A case study, International Journal of Pharmacy and Technolog, 7, 9610-9622.

Qi H., Li W-L., Zhu N-Z., Ma W-L., Liu L-Y., Zhang F. and Li Y-F. (2014), Concentrations and sources of polycyclic aromatic hydrocarbons in indoor dust in China, Science of the Total Environment, 491, 100-107.

Raeisi A., Arfaeinia H., Seifi M., Shirzad-Siboni M., Keshtkar M. and Dobaradaran S. (2016), Polycyclic aromatic hydrocarbons (PAHs) in coastal sediments from urban and industrial areas of Asaluyeh Harbor, Iran: distribution, potential source and ecological risk assessment, Water Science and Technology, 74, 957-973.

Rasmussen P., Subramanian K. and Jessiman B. (2001), A multielement profile of house dust in relation to exterior dust and 
soils in the city of Ottawa, Canada, Science of the Total Environment, 267, 125-140.

Ren Y., Cheng T. and Chen J. (2006), Polycyclic aromatic hydrocarbons in dust from computers: one possible indoor source of human exposure, Atmospheric Environment, 40, 6956-6965.

Roberts J.W., Wallace L.A., Camann D.E., Dickey P., Gilbert S.G., Lewis R.G. and Takaro T.K. (2009), Monitoring and reducing exposure of infants to pollutants in house dust. In "Reviews of Environmental Contamination and Toxicology Vol 201", pp. 139. Springer.

Rudel R.A., Camann D.E., Spengler J.D., Korn L.R. and Brody J.G. (2003), Phthalates, alkylphenols, pesticides, polybrominated diphenyl ethers, and other endocrine-disrupting compounds in indoor air and dust, Environ. Sci. Technol., 37, 4543-4553.

Singh D., Gadi R. and Mandal T.K. (2011), Characterization of particulate-bound polycyclic aromatic hydrocarbons and trace metals composition of urban air in Delhi, India, Atmospheric Environment, 45, 7653-7663.

Song H.M. and Xu L.Y. (2011), A method of urban ecological risk assessment: combining the multimedia fugacity model and GIS, Stochastic Environmental Research and Risk Assessment, 25, 713-719.

Stuart H., Ibarra C., Abdallah MA-E., Boon R., Neels H. and Covaci A. (2008), Concentrations of brominated flame retardants in dust from United Kingdom cars, homes, and offices: causes of variability and implications for human exposure, Environment international, 34, 1170-1175.

Tao Y., Li F., Crittenden J.C., Lu Z. and Sun X. (2016), Environmental Impacts of China's Urbanization from 2000 to 2010 and Management Implications, Environmental Management, 57, 498-507.

Whitehead T., Metayer C., Buffler P. and Rappaport S.M. (2011), Estimating exposures to indoor contaminants using residential dust, Journal of Exposure Science and Environmental Epidemiology, 21, 549-564.

Wolkoff P. (2013), Indoor air pollutants in office environments: assessment of comfort, health, and performance, International journal of hygiene and environmental health, 216, 371-394.

Xia Z., Duan X., Qiu W., Liu D., Wang B., Tao S., Jiang Q., Lu B., Song $\mathrm{Y}$. and $\mathrm{Hu}$ X. (2010), Health risk assessment on dietary exposure to polycyclic aromatic hydrocarbons (PAHs) in Taiyuan, China, Science of the Total Environment, 408, 53315337.

Xu L. and Shu X. (2012), Approach for aggregate risk assessment of urban development zones, Procedia Environmental Sciences, 13, 288-296.

Xu L. and Shu X. (2014), Aggregate human health risk assessment from dust of daily life in the urban environment of Beijing, Risk analysis, 34, 670-682.

Yang Q., Chen H. and Li B. (2015), Polycyclic aromatic hydrocarbons (PAHs) in indoor dusts of Guizhou, southwest of China: Status, sources and potential human health risk, PloS one, 10, e0118141. 